\title{
Leukemic Stem Cells Shows the Way for Novel Target of Acute Myeloid Leukemia Therapy
}

\section{Adhra Al-Mawali*}

Director of Research and Studies. Directorate of Research and Studies, Directorate General of Planning, Ministry of Health, PO Box 393, PC 111, Muscat, Sultanate of Oman

\begin{abstract}
Leukemic stem cells (LSCs) have been identified in acute myeloid leukemia (AML). Similar to haematopoietic stem cells, these LSCs are able to self-renew, differentiate, and proliferate extensively. Recent studies suggest that LSCs are critical for the initiation and maintenance of leukemia.

This review will describe the characteristic features of LSCs in AML and the possible targets expressed on the surface of $A M L$, the intracellular targets and the novel molecular and flow cytometry methodologies being used to particularly ablate the LSC population.

Studies have shown the potential importance of ablating LSCs when treating leukemia. The unique characteristics of LSCs that differentiate them from their normal counterparts can be applied to specifically target the leukemic population.

Current therapeutic strategies may not effectively ablate the LSCs, leaving the potential for disease progression or recurrence. A better understanding of LSCs and molecular biology will allow the design of more effective therapies.
\end{abstract}

Keywords: Leukemia; Leukemic stem cells; Acute myeloid leukemia; Stem cell therapy; LSCs

\section{Introduction}

Acute myeloid leukemia (AML) is one of the most common leukemia's in adults. AML is characterized by an accumulation of undifferentiated and functionally heterogeneous populations of cells $[1,2]$. Relapse of the disease is thought to occur because of the failure of chemotherapy to eradicate LSCs [3]. LSCs have been defined as $\mathrm{CD} 34^{+} \mathrm{CD} 38^{-}$cells with the ability to reconstitute marrow of mice with severe combined immunodeficiency (SCID)-repopulating ability, which is a reflection of their capacity to self-renew [4,5].

In order for any AML therapy to be curative, it needs to be effective against the cells that propagate and sustain the disease, the so called LSCs. However, previous studies suggest that LSCs are biologically distinct from more mature leukemic blasts and may not be responsive to conventional chemotherapeutic regimens [6,7]. In 1997, Bonnet and Dick described the phenotype for LSCs as CD34 ${ }^{+} / \mathrm{CD} 38^{-}$[4]. Subsequent studies showed that LSCs are also CD34 $/ \mathrm{HLA}-\mathrm{DR} / \mathrm{CD} 71^{-}$and fail to express Thy-1 $[5,8]$. Numerous studies have attempted to distinguish leukemic from normal stem cells. One potential difference between normal and leukemic cells lies in their response to haematopoietic growth factors. Several studies have examined the cytokine response of primary leukemia cells and demonstrated mitogenic activity for interleukin-3 (IL-3), granulocyte colony-stimulating factor (G-CSF), granulocyte-macrophage colony-stimulating factor (GM-CSF), stem cell factor (SCF), thrombopoietin (TPO) and other factors [9-11].

Over the last few years, the functional properties and phenotype of human LSCs have begun to be explored. Today, AML stem cells can be discriminated and separated from normal stem cells and from more mature AML cells [12-16]. Due to their repopulating and disease-maintaining effects, these cells appear to be a most important target cell population in the context of curative therapies. Therefore, a number of studies are presently focusing on AML stem cells and on effective drugs that can attack these cells in a target-dependent manner.
The currently available data are promising and point to the potent anti-leukemic effects of 'stem cell-targeted' drug therapy [14,17-22]. However, these data also show that many targets and pathways still need to be explored. The most promising approach for future concepts may be to target multiple extracellular and intracellular targets and unrelated downstream signalling pathways in AML stem cells by the co-administration of various targeted drugs (advanced targeted drug therapy). Whether these strategies will help in the eradication of AML clones and the management of minimal residual AML remains to be determined in future clinical trials.

Thus, there is compelling evidence that the precise predisposing or suppressing cellular and molecular factors of relapses in patients in complete remission (CR) remain to be determined. It is becoming evident that relapses occur in patients in whom the leukemic cells survive chemotherapy, which show evidence of functional properties of stem cells [23]. A number of observations proposed that AML clones in each patient represent a heterogeneous mixture of cells with varying phenotypic and functional properties [1,4,5,8,23-25]. In particular, despite differentiation and maturation arrest, AML clones are organized in a hierarchical manner similar to normal haematopoietic cells $[1,4,24,26]$. On the top of this hierarchy, LSCs act as AMLinitiating and maintaining cells, whereas their more mature progeny-

*Corresponding author: Adhra Al-Mawali PhD, Director of Research and Studies Directorate of Research and Studies, Directorate General of Planning, Ministry of Health, PO Box 393, PC 111, Muscat, Sultanate of Oman, Tel: +968 24697551; Fax: +968 24696702; E-mail: adhra.almawali@gmail.com, adhra.hilal@moh.gov.om

Received July 23, 2013; Accepted September 18, 2013; Published September 20, 2013

Citation: Al-Mawali A (2013) Leukemic Stem Cells Shows the Way for Nove Target of Acute Myeloid Leukemia Therapy. J Stem Cell Res Ther 3: 151 doi:10.4172/2157-7633.1000151

Copyright: (c) 2013 Al-Mawali A. This is an open-access article distributed under the terms of the Creative Commons Attribution License, which permits unrestricted use, distribution, and reproduction in any medium, provided the original author and source are credited. 
cells are unable to maintain the long-term growth of leukemia $[1,4,24]$. This hypothesis has been confirmed for various subtypes of AML by utilizing repopulation assays $[1,24]$.

LSCs obtained from patients with AML are defined by their AML repopulating capacity in vivo, i.e. their ability to give rise to leukemia's in immunodeficient mice $[1,4,24]$. Over the last few years, these cells have been characterized in terms of their frequency in AML clones, their phenotype, and their functional properties. Similar to normal haematopoietic stem cells (HSCs), LSCs represent only a small fraction of cells within a given AML clone $\left(0 \cdot 2-100\right.$ cells in $10^{6}$ cells) [4]. In common with their daughter cells, most LSCs express CD34 [1,27-29].

In addition, LSCs despite being present in low numbers may be responsible for the relapses in AML and therefore are considered to contribute essentially to the pathology and clinical outcome in these patients. So rather than monitoring the whole blasts cell population, it may be more relevant to search for the residual LSCs.

\section{Functional and Phenotypic Characterization of Leukemic Stem Cells}

\section{Functional characterization of LSCs}

AML-LSCs are found to be non-cycling and present in the endosteal region of the bone marrow [30]. Analogous to the repopulating potential of HSCs, LSCs have the potential to repopulate haematopoietic tissues in severe combined immunodeficient (SCID) mice $[1,4,24,26]$. Though, only a small sub-fraction of cells within leukemic clones represent LSCs, whereas the vast majority of AML cells in a given clone are unable to repopulate SCID mice with leukemia $[1,4]$. The capacity of LSCs to self-renew in vivo is further supported by the fact that the leukemic cells that can be generated from these cells in SCID mice can again give rise to leukemia when serially transplanted into 'secondary' cohorts of SCID mice [4]. The morphology and the immunophenotype of the LSC-derived AML cells in these SCID mice are identical to the original AML clone [4]. The capability of stem cells to be dormant and remain in their respective bone marrow niches protected from antagonistic influences allows for maintenance of their self-renewal activity [30]. These results demonstrate the potential of LSCs to initiate the re-growth of AML cells in vivo (Figure 1). Based on this finding, it is tempting to speculate that LSCs represent those residual AML cells (Minimal Residual Disease or MRD) [31-34] that can regrow to overt relapsing leukemia's after chemotherapy or bone marrow transplantation.

An important aspect of LSCs in patients with AML is that a high percentage of them appear to be quiescent (Ki67-negative), thus contrasting with the high cell burden and potentially aggressive clinical course of these leukemia's [35]. This observation may explain why these LSCs are often less responsive against cell cycle-active chemotherapeutic agents compared to their more mature progeny. Even though LSCs reportedly express receptors for IL-3 and other cytokines, it remains unknown whether such cytokines can induce the growth or/and differentiation of LSCs. Taussig et al. [36] reported that leukemia-initiating cells (LIC's) were found to be present in the CD34- fraction in a significant amount of AML's. They also showed that the phenotype of LIC's is heterogeneous in AML. It is this feature of LIC's which can make it difficult for targeting therapies against surface antigens. Furthermore, it was also shown that LIC's were not found in the CD34 CD38 fraction in approximately half of the NPM (Nucleophosmin) gene-mutated AML's [36]. NPM1 is a gene which has both tumor-suppressor and oncogenic functions. A disruption of the NPM nucleolar-localization signal occurs with mutations of NPM, causing accumulation of NPM in the cytoplasm. The NPM1 gene rearranges with the retinoic acid receptor a (RARa) in AML $[37,38]$. Also, although Jordan et al. [35] have shown that IL-3a receptor (CD123) is detectable on LSCs and not HSCs, little is known about their exact functional role in LSCs.

\section{Phenotypic characterization of LSCs}

Previous studies demonstrate that LSCs are mainly found

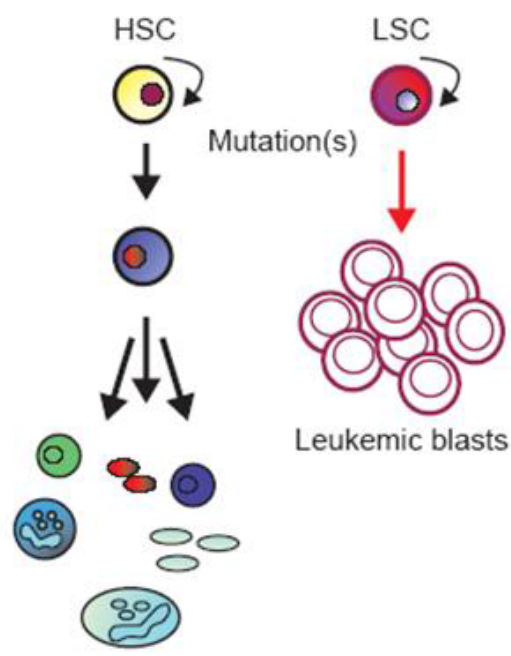

Normal differentiated A hematopoietic cells

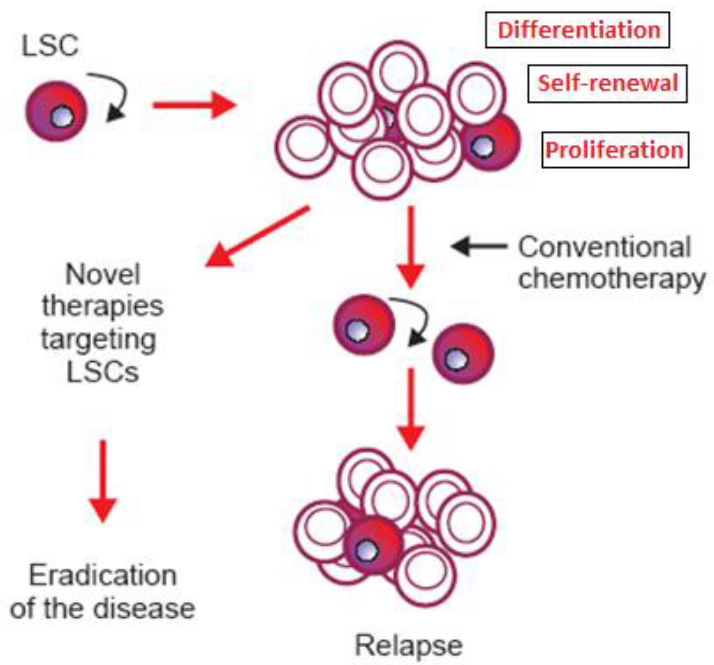

B

Figure 1: (A) The leukemic stem cell (LSC) model proposes that leukemic blasts originate from a common primitive progenitor that has the capacity to self-renew. (B) Conventional therapy for leukemia has been designed to eliminate leukemic blasts. These therapies may not effectively eradicate the LSC population which have the functional characteristics of self-renewal, differentiation and proliferation, which ultimately recapitulates the disease [67]. 
Citation: Al-Mawali A (2013) Leukemic Stem Cells Shows the Way for Novel Target of Acute Myeloid Leukemia Therapy. J Stem Cell Res Ther 3: 151. doi:10.4172/2157-7633.1000151

within the $\mathrm{CD}^{+} 4^{+} \mathrm{CD} 38^{-} \mathrm{Lin}^{-}$subset of the leukemic clone (Figure 2) $[4,24,39]$. Other clonal leukemic cells with a more mature phenotype are unable to initiate AML in vivo [1,24]. These data are similar to the repopulation characteristics of normal human HSCs in SCID mice $[1,4,23,24,27,40,41]$. However, despite phenotypic and functional similarities, it has to be highlighted that slight differences in the cell surface phenotype are found when comparing normal HSCs with LSCs. Similarly, LSCs, but not HSCs, express the IL-3 receptor a chain (CD123) $[35,42,43]$. Another marker that is detectable on LSCs in (a subset of) patients with AML, is Siglec-3 (CD33) [44,45]. In addition, LSCs may also show immunophenotypic heterogeneity concerning other surface molecules such as CD116 (GM-CSFRa), CD117 (SCFR), or CD71 $[5,8,25,46]$.

C-type lectin-like molecule-1 (CLL-1) has also been shown to be expressed in LSCs and not HSCs [16]. CD $34^{+}$CD 38 CLL- $1^{+}$cells were found to engraft NOD/SCID mice and a high CLL- $1^{+}$fraction was associated with quick relapse. In this regard, CLL-1 may serve as a marker for quantification of minimal residual stem cell disease. Further, CD44, an adhesion molecule, has also recently been described as a target on $\mathrm{CD} 34^{+} \mathrm{CD} 38^{-}$cells [20]. It was shown that the activating antibody $\mathrm{H} 90$ results in differentiation of cells and in a major reduction of engraftment in NOD/SCID mice. However, CD44 is also weakly expressed on normal $\mathrm{CD} 34^{+} \mathrm{CD} 38^{-}$cells and on more differentiated haematopoietic cells. It is also a key regulator of AML-LSCs homing to microenvironmental niches [20].

Phenotypic differences between LSCs and HSCs may be of great value. These differences allow discrimination of these cells by flow cytometry assays and to separate LSCs from HSCs for genetic analyses. Markers specific for LSCs may prove suitable targets for the development of novel therapies; because otherwise normal HSCs would also be eradicated, and such an approach would then only be possible when combining with a transplantation strategy. As LSCs are responsible for relapse, they may also be used for MRD (Minimal Residual Disease) detection.

\section{Targets of AML Therapy Detectable in Leukemic Stem Cells}

The challenge is to identify proapoptotic stimuli that spare the normal HSCs while exerting the desired effect on LSCs. The key for targeting LSCs is by targeting drug efflux pumps, targeting cell cycle, targeting cell surface antigens, targeting NF- $\kappa B$ activity, targeting cell differentiation, targeting leukemia stem cells via active specific immunization and targeting other pathways involved in self-renewal. Molecular constructions in AML cells that may serve as targets of

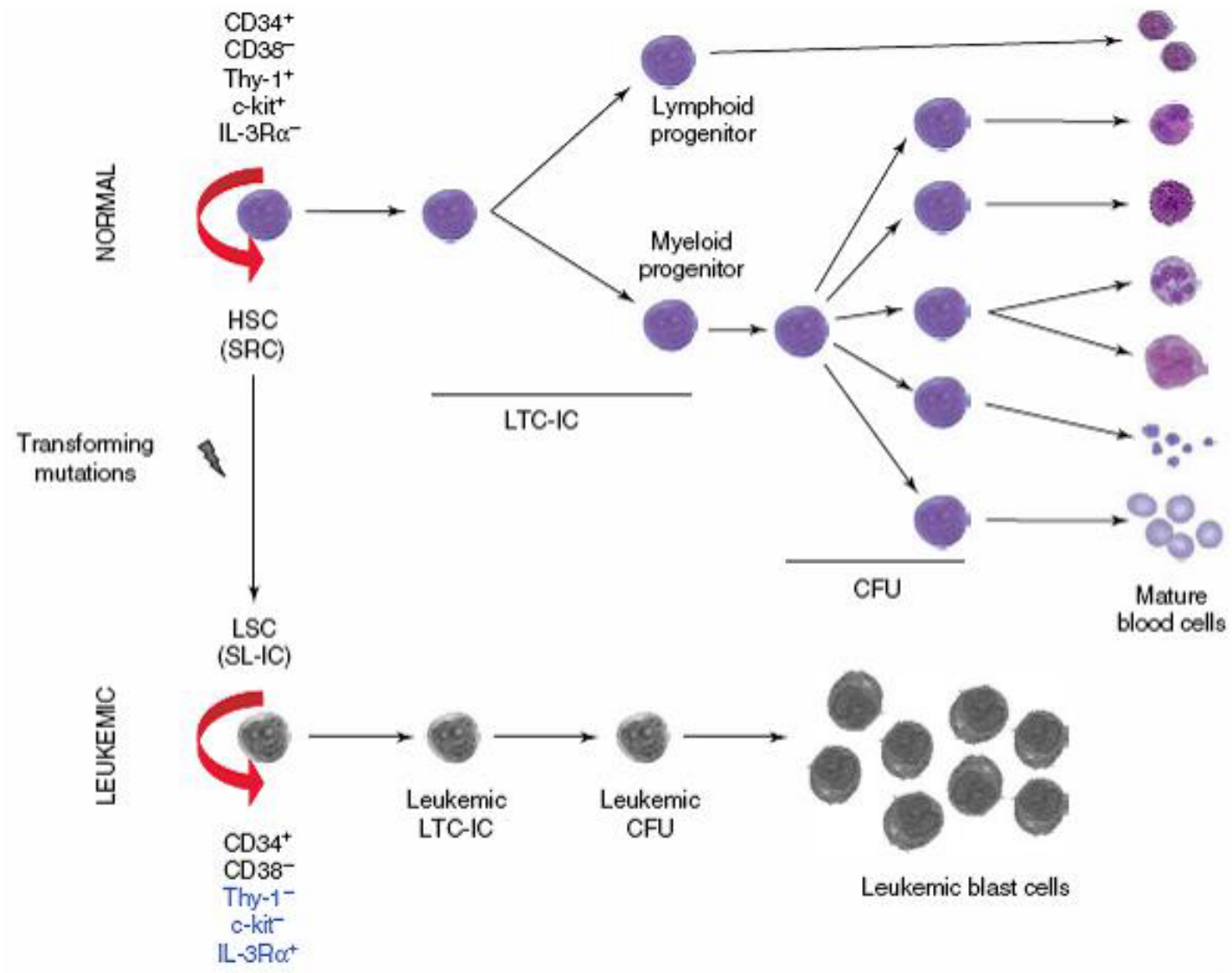

Figure 2: Schematic illustration of the normal and leukemic human haematopoietic hierarchies. Human haematopoietic cells are organized in a hierarchy that is sustained by a small population of self-renewing HSCs. HSCs give rise to progressively more lineage-restricted, differentiated progenitors with reduced self-renewal capacity (LTC-ICs, long-term culture-initiating cells; CFU, colony-forming units), which in turn produce functionally mature blood cells. Disruption of pathways regulating self-renewal and differentiation through the acquisition of transforming mutations generates LSCs capable of sustaining growth of the leukemic clone in vivo. LSCs possess an altered differentiation program, as demonstrated by aberrant expression of some cell-surface markers (indicated in purple) and give rise to an aberrant developmental hierarchy that retains aspects of its normal counterpart. In vivo, reconstitution assays using immune-deficient mouse recipients enable detection of HSCs and LSCs as SCID-repopulating cells (SRCs) and SCID leukemia-initiating cells (SL-ICs), respectively [39]. 
specific therapy are located in various compartments of the leukemic cell. Generally, such targets are either detectable on the cell surface or within the cytoplasm (Table 1) [47].

\section{Targets expressed on the surface of AML leukemic stem cells}

Based on target molecules expressed on the surface of leukemic cells, a number of new treatment strategies have recently been established [22,45,48-51]. One of these concepts employs humanized antibodies $(\mathrm{Ab})$ conjugated with a cytostatic drug. These conjugates bind to leukemic cells through an interaction of the $\mathrm{Ab}$ with the target structure on the surface of AML blasts. Consecutively, the Ab-drug conjugate is internalized by the leukemic cells. After internalization, the drug is released from the $\mathrm{Ab}$ and inhibits critical cell functions (depending on the nature of the cytostatic drug) and eventually leads to cell death $[22,49,52,53]$. An important example for such conjugates is Mylotarg (gemtuzumab/ozogamicin), which consists of a humanized anti-Siglec-3 antibody (CD33) and the highly potent (toxic) cytostatic drug calicheamicin $[22,49,52,54]$. However, it has been found that patients are prone to relapse despite being effective at inducing remission in some patients, which raises the question of the resistance of LSCs to the toxic drug [55].

Furthermore, anti-interleukin-3 (IL-3) receptor alpha chain (CD123)-neutralizing antibody (7G3) targeted AML-LSCs, impairing homing to bone marrow and activating innate immunity of NOD/SCID mice. 7G3 treatment profoundly reduced AML-LSCs engraftment and improved mouse survival. Mice with pre-established disease showed reduced AML burden in the bone marrow and periphery and impaired secondary transplantation upon treatment, establishing that AML-LSCs were directly targeted. 7G3 inhibited IL-3-mediated intracellular signaling of isolated $\mathrm{AML} \mathrm{CD} 34^{+} \mathrm{CD} 38^{-}$cells in vitro and reduced their survival. These results provide clear validation for therapeutic monoclonal antibodies (MoAbs) targeting of AML-LSCs and for translation of in vivo preclinical research findings toward a clinical application [14]. In one study [56], it was shown that there was significant correlation of $\mathrm{CD} 34^{+} \mathrm{CD} 38^{-} \mathrm{CD} 123^{+}$leukemic cells at diagnosis with response to post-induction treatment and survival. As a result, it was also suggested that adverse outcomes in AML could be predicted by high levels of $\mathrm{CD} 34^{+} \mathrm{CD} 38^{-} \mathrm{CD} 123^{+}$[56]. Proportions of LSCs expressing CD123 measured by multiparametric flow cytometry [32] were found to be significantly lower in the complete remission (CR) group compared with the non-CR group. This could help predict prognosis of AML by measurement of the proportion of LSCs [15].

CD47, a cytokine receptor similar to CD123, is a transmembrane protein that serves as a ligand for signal regulatory protein (SIRPa) and is found to be upregulated on AML-LSCs than on HSCs. An increased expression of CD47 on LSCs contributed to pathogenesis by inhibiting phagocytosis through the interaction of CD47 with an inhibitory receptor on phagocytes. Thus, increased CD47 expression proved to be an independent poor prognostic factor. Targeting of human AML stem cells by blocking MoAbs directed against CD47 preferentially enabled phagocytosis of AML LSCs. Elimination of human cancer cells in xenograft models of AML by this targeting method was studied and the level of expression of CD47 on AML-LSCs was found to be associated with poor prognosis [19].

Another marker which can be expressed on the surface on LSCs is CD96. CD96, a member of the Ig gene super family, has been shown to be expressed in a majority of the LSCs population and at a much lower frequency in HSCs. CD96 $6^{+}$AML cells are highly enriched for LSCs activity compared to CD96 AML cells. The presence of CD96 expression allows AML-LSCs to be distinguished from normal HSCs [21]. Thus, CD96 is a cell surface marker which can serve as an LSCspecific therapeutic target. Also recently, it was shown that CD96specific antibodies can efficiently activate ADCC (Antibody dependent cell-mediated cytotoxicity) which is an important $\mathrm{Fc}$ receptor mediated effector mechanism for the in vivo activity of therapeutic antibodies.

\begin{tabular}{|c|c|c|c|c|c|}
\hline & \multirow{2}{*}{ Antigen } & \multirow{2}{*}{ Function/Characteristics } & \multicolumn{2}{|c|}{ Expression } & \multirow{2}{*}{ Reference } \\
\hline & & & LSCs & HSCs & \\
\hline \multirow{7}{*}{ 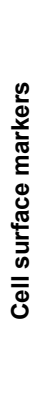 } & CD123 & High affinity IL-3 receptor (IL-3a) & + & - & Jordan et al. (2000) \\
\hline & CD47 & Ligand for SIRPa, inhibits phagocytosis & + & - & Majeti et al. (2009) \\
\hline & CD96 & $\begin{array}{l}\text { Activation of Antibody dependent cell-mediated } \\
\text { toxicity }\end{array}$ & $++^{*}$ & + & Hosen et al. (2007) \\
\hline & CD32 & Fc-g receptor 2 (FCGR2) & + & - & Saito et al. (2010) \\
\hline & CD25 & High-affinity IL-2 receptor (IL2Ra) & + & - & Saito et al. (2010) \\
\hline & CD44 & $\begin{array}{l}\text { Facilitates adhesive interactions, key regulator of } \\
\text { AML-LSCs homing to microenvironmental niches }\end{array}$ & $++^{*}$ & + & Jin et al. (2006) \\
\hline & CXCR4 & $\begin{array}{l}\text { Cell membrane receptor, contributes to SDF-1 } 1 \text { / } \\
\text { CXCR4 interactions }\end{array}$ & $++^{*}$ & + & Spoo et al. (2007) \\
\hline \multirow{4}{*}{ 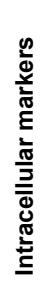 } & AurA & $\begin{array}{l}\text { Mitotic serine/threonine kinases that play a role in } \\
\text { cytokinesis during mitosis and cell division }\end{array}$ & $++^{*}$ & + & Ochi et al. (2009) \\
\hline & Mcl-1 & $\begin{array}{l}\text { Plays a critical role in maintenance and survival } \\
\text { of LSCs }\end{array}$ & $++^{*}$ & + & Yoshimoto et al. (2009) \\
\hline & TIM-3 & $\begin{array}{l}\text { Regulator of macrophage activation, role with } \\
\text { complement-dependent and antibody dependent } \\
\text { cell-mediated cellular cytotoxic activities }\end{array}$ & + & - & Kikushige et al. (2010) \\
\hline & NF-kB & $\begin{array}{l}\text { Transcription factor, responsible for LSC } \\
\text { antiapoptotic activity }\end{array}$ & + & - & Guzman et al. (2001) \\
\hline
\end{tabular}

Abbreviations: IL, interleukin; SIRPa, signal regulatory protein $\alpha$; SDF, stromal cell-derived factor; LSCs, leukemic stem cells; HSCs, haematopoietic stem cells; CXCR4, C-X-C chemokine receptor type 4; AurA, Aurora A kinase; Mcl-1, myeloid cell leukemia-1; TIM-3, T cell immunoglobulin mucin-3; NF-KB, nuclear factor-KB. *Increased expression

Table 1: Significant cell surface and intracellular targets in AML-LSCs. 
However, in a clinical setting, future studies are yet to determine whether or not the single chain fragment of the variable regions fusion proteins (scFv-based mini-antibodies) will be able to eradicate AMLLSCs [57].

Differential analysis of genes using microarrays as well as protein expression by flow cytometry revealed two cell surface markers, CD32 and CD25 (that are normally expressed on B and T cells) which were found to be highly expressed in human AML-LSCs and not expressed in normal HSCs. They were also found to be stably present in the all-important cell cycle-quiescent, AML initiating cells in the endosteal niche that might be the cause for AML relapse. Xenogeneic transplantation has shown that HSC function could be eliminated from the $\mathrm{CD} 34^{+} \mathrm{CD} 38^{-} \mathrm{CD} 25^{-}$and $\mathrm{CD} 34^{+} \mathrm{CD} 38^{-} \mathrm{CD} 32^{-}$fractions of human cord blood, thus confirming that targeting of CD32 or CD25 would not compromise normal HSC development [12]. This could facilitate the development of therapeutic strategies in AML because they were present in a significant number of AML patients, especially the poorrisk population $[12,13,58]$.

CXC chemokine receptor (CXCR4), another marker for LSCs on the surface, is a cell membrane receptor is found on stem cells [5961]. It has been found that SDF-1a (stromal cell-derived factor-1) / CXCR4 interactions contribute to the resistance of LSCs to apoptosis in the microenvironment. Effective targeting of CXCR4 and its interactions paves the way to eliminate and target cells that are usually protected by the bone marrow microenvironment [62]. Recently, it was suggested that CXCR4 expression is associated with poor prognosis in AML patients and a marker of more aggressive disease in a normal karyotype AML population [63]. This can even be incorporated into risk assessment of AML patients [18,63].

\section{Intracellular targets of AML therapy}

Over the past few years, a large number of cytoplasmic and nuclear target structures in AML cells have been identified [17,64-66]. Among these are DNA-methylating enzymes, histone deacetylases, leukemiaspecific fusion gene-products (such as promyelocytic leukemia gene/ RAR $\alpha$ PML/RAR $\alpha$ ), pro-oncogenic transcription factors (Signal Transducer and Activator of Transcription $\{$ STAT $\}$-family, Ets, c-Myb, HOX, NF- $\kappa B$, others) and critical elements in pro-oncogenic signal transduction cascades (Receptor tyrosine kinases \{RTKs\}, mutated oncogenic forms of Ras, others) [66].

Nuclear factor $\kappa \mathrm{B}(\mathrm{NF}-\kappa \mathrm{B})$ is constitutively expressed in blast cells in a majority of patients with AML $[64,67,68]$. Additionally, NF- $\kappa B-$ activity is detectable in the quiescent LSC population in these patients, whereas normal HSCs do not express NF- $\kappa B$ activity [64,68]. Thus, trying to eradicate LSCs by direct targeting using NF- $\mathrm{kB}$ pathway could be a potential therapeutic strategy $[69,70]$.

Recent reports have identified and applied a number of different tyrosine kinase inhibitors in clinical trials in leukemic patients [71-82]. Important stem cell RTKs expressed in AML cells are the SCF receptor KIT, macrophage colony-stimulating factor (M-CSF) receptor FMS, PDGFR $\beta$, fms-related tyrosine kinase-1 (FLT1) and FLT3 [66,81,83,84]. At least some of these tyrosine kinases are also expressed in LSCs [71].

Several previous and more recent observations suggest that these molecules do play an important role in leukemogenesis $[66,81,83,85,86]$. Similarly, the FLT3 gene is the most frequently mutated gene in patients with AML $[66,83,84,86,87]$. These mutations lead to ligandindependent dimerization of the receptor and its auto-phosphorylation with consecutive activation of multiple signal transduction pathways including the STAT5-, RAS/MAPK- and phosphoinositide 3-kinase/ AKT-pathway (PI3/AKT) [88]. Since these mutations apparently act pro-oncogenically, it is appealing to speculate that they all take place and are detectable at the stem cell level in patients with AML.

A number of drugs targeting RTKs have recently been applied to AML cells in clinical and/or pre-clinical trials. Likewise, the inhibition of FLT3 by AG1296 or Herbimycin A in AML cells in mice was found to counteract the progression of leukemia $[66,83]$. In addition, a number of targeting drugs directed against RTKs have been developed in recent years, including CEP701, CEP751, SU5614, SU5416, SU11248 and PKC412 [71,76-82,89]. These inhibitors may act on several RTKs including FLT3, thus inhibiting proliferation of leukemic cells. Additionally, some of these inhibitors have already been evaluated in vivo. Likewise, CEP701 has been reported to induce responses in AML patients' refractory to conventional chemotherapy [79]. Interestingly, at least some of these RTK-type receptors are known to be expressed in AML-LSCs.

Recently, a novel and promising therapeutic strategy to preferentially target human AML-LSCs was uncovered by lysosome disruption [90]. An important finding of this study was that AMLLSCs were found to be enriched in bulk AML cells and their subsets which showed increased lysosomal size and biogenesis after lysosome disruption in human AML cells. This research study has shown that some common biological features and mechanisms remain open to selective targeting even though AML biology is so widely known as heterogeneous [90].

A breakthrough intracellular target for AML-LSCs is Aurora A kinases (AurA) which are a family of mitotic serine/threonine kinases that play a role in cytokinesis during mitosis and cell division [91,92]. AurA showed a significant higher level of expression in AML-LSCs than in HSCs and can be used as a marker. Kim et al. [93] showed that specific AurA inhibitors could be used to reduce AML-LSCs. The study also further found that the reduction of AML-LSCs could be enhanced with stimulation with G-CSF and the use of AurA inhibitors [93]. Further studies confirmed that AurA inhibitors significantly inhibited proliferation, impaired self-renewal capacity and induced apoptosis of AML-LSCs as well as prolonged survival when AurA inhibitors were used during engraftment of $\mathrm{CD} 34^{+} \mathrm{CD} 38^{-}$AML cells in severely immunocompromised mice [94].

Another therapeutic target for AML-LSC therapy present intracellularly is myeloid cell leukemia-1 (Mcl-1), which has been found to be up-regulated during AML relapses in FLT3/ITD AML-LSCs. This could probably be due to the fact that Mcl-1 confers some sort of resistance to chemotherapy [95]. Mcl-1 has been suggested to promote survival of FLT3/ITD AML-LSCs via a STAT5-dependent pathway that is independent of normal FTL3 signaling [96]. Furthermore, deletion of Mcl-1 led to induced death of transformed AML and eradicated disease in the AML NOD/SCID mice [97]. So, the lowering of Mcl- 1 through a variety of approaches such as disruption or degradation of Mcl-1 by $\mathrm{Bcl}-2$ inhibitors and other inhibitors, interfering with transcription and translation processes and targeting STAT5-dependent pathway makes Mcl-1 a favorable therapeutic target in AML-LSCs [96,98]. Studies also suggest that combination approaches which disrupt multiple prosurvival pathways and activate their pro-apoptotic pathways could be promising for targeting [98].

$\mathrm{T}$ cell immunoglobulin mucin-3 (TIM-3), normally found as 
a surface molecule expressed in $\mathrm{CD} 4^{+}$Th1 lymphocytes in mouse haematopoiesis, is another promising target to eradicate AML-LSCs as it has been found to be expressed on LSCs but not on HSCs. TIM3 functions as a regulator of macrophage activation as well as having a role in complement-dependent and antibody dependent cellmediated cellular cytotoxic activities. When TIM-3 was targeted using monoclonal antibody treatment, it inclined to eradicate AML-LSCs without affecting normal HSCs in mouse models $[99,100]$.

\section{Summary and Future Directions}

AML populations are consisted of hierarchical structure and in recent years it has been possible to begin analyzing individual constituents of the leukemic clone. Although, varying AML subtypes differentiate to differing levels, it has become increasingly evident that important similarities exit at the top of the developmental hierarchy.

Given the quiescent status of LSCs and their relatively low frequency, ablation of this population is likely to be a significant challenge. Despite the fact that a variety of LSC characteristics are almost identical to normal HSCs, recent studies of AML molecular biology and immunophenotypic characteristics suggest that some differences between normal and leukemic cells are apparent in the stem cell/progenitor cell pool $[14,43,101,102]$. From a therapeutic perspective, this observation is extremely important because it suggests LSCs do have unique characteristics that may make them preferentially sensitive to apoptosis/ablation. This information also serves to emphasize the importance of better understanding LSCs and how they differ from normal HSCs.

By establishing general parameters for induction of LSC apoptosis, it should be potential to develop more effective clinical therapies. Given the heterogeneity of mutations that give rise to these malignancies, the ability to target the malignant population is not likely to be achieved by a single specific inhibitor. To this end, it is fundamental to completely understand the signaling pathways that regulate survival and death in LSC populations. Current studies have started to characterize molecular mechanisms that may be relevant to LSC survival. However, more comprehensive methodologies using multiparameter or combined approaches should be the priority for future studies [12$15,32,33,56,102,103]$.

Combining different MoAbs may also target a larger proportion of the heterogeneous AML population, overcoming possible clonal selection, as well as evasion by epitope down regulation, as has been shown in lymphoma after treatment with CD20 targeting rituximab [104]. An AML patient surface immunophenotype is relatively costeffective to characterize, raising the possibility of tailored therapy based on a selection of available MoAbs. Indeed, we are entering a new and exciting era in the struggle to improve outcome in adult AML.

\section{Acknowledgements}

The author would like to thank Avinash Daniel Pinto for assistance and input in improving the quality of this manuscript. The author would also like to acknowledge The Research Council of Oman (TRC) for sponsoring this work (Grant Number 47).

\section{References}

1. Appelbaum FR, Rowe JM, Radich J, Dick JE (2001) Acute myeloid leukemia. ASH Education Book 2001: 62-86.

2. Lowenberg B, Downing JR, Burnett A (1999) Acute myeloid leukemia. N Engl J Med 341: 1051-1062.

3. van Rhenen A, Feller N, Kelder A, Westra AH, Rombouts E, et al. (2005) High stem cell frequency in acute myeloid leukemia at diagnosis predicts high minimal residual disease and poor survival. Clin Cancer Res 11: 6520-6527.
4. Bonnet D, Dick JE (1997) Human acute myeloid leukemia is organized as a hierarchy that originates from a primitive hematopoietic cell. Nat Med 3: 730737.

5. Blair A, Hogge DE, Sutherland HJ (1998) Most acute myeloid leukemia progenitor cells with long-term proliferative ability in vitro and in vivo have the phenotype CD34(+)/CD71(-)/HLA-DR. Blood 92: 4325-4335.

6. Terpstra W, Ploemacher RE, Prins A, Van Lom K, Pouwels K, et al. (1996) Fluorouracil selectively spares acute myeloid leukemia cells with long-term growth abilities in immunodeficient mice and in culture. Blood 88: 1944-1950.

7. Terpstra W, Prins A, Ploemacher RE, Wognum BW, Wagemaker G, et al. (1996) Long-term leukemia-initiating capacity of a CD34-subpopulation of acute myeloid leukemia. Blood 87: 2187-2194.

8. Blair A, Hogge DE, Ailles LE, Lansdorp PM, Sutherland HJ (1997) Lack of expression of Thy-1 (CD90) on acute myeloid leukemia cells with long-term proliferative ability in vitro and in vivo. Blood 89: 3104-3112.

9. Smith MA, Smith JG, Pallister CJ, Singer CR (1996) Haemopoietic growth factors, the cell cycle of acute myeloblastic leukaemia progenitors and sensitivity to cytosine arabinoside. Leuk lymphoma 23: 467-472.

10. Murayama T, Imoto S, Natazuka T, Chihara K, Matsui T (1998) Proliferative reaction of myelogenous leukemia cells with cytokines G-CSF, GM-CSF, M-CSF, SCF and TPO. Leuk Res 22: 557-560

11. Ailles LE, Gerhard B, Hogge DE (1997) Detection and characterization of primitive malignant and normal progenitors in patients with acute myelogenous leukemia using long-term coculture with supportive feeder layers and cytokines. Blood 90: 2555-2564.

12. Saito $\mathrm{Y}$, Kitamura H, Hijikata A, Tomizawa-Murasawa M, Tanaka S, et al (2010) Identification of therapeutic targets for quiescent, chemotherapyresistant human leukemia stem cells. Sci Transl Med 2: 17ra9.

13. Majeti R (2011) Monoclonal antibody therapy directed against human acute myeloid leukemia stem cells. Oncogene 30: 1009-1019.

14. Jin L, Lee EM, Ramshaw HS, Busfield SJ, Peoppl AG, et al. (2009) Monoclona antibody-mediated targeting of CD123, IL-3 receptor alpha chain, eliminates human acute myeloid leukemic stem cells. Cell Stem Cell 5: 31-42.

15. Hwang K, Park CJ, Jang S, Chi HS, Kim DY, et al. (2012) Flow cytometric quantification and immunophenotyping of leukemic stem cells in acute myeloid leukemia. Ann Hematol 91: 1541-1546.

16. van Rhenen A, van Dongen GA, Kelder A, Rombouts EJ, Feller N, et al. (2007) The novel AML stem cell associated antigen CLL-1 aids in discrimination between normal and leukemic stem cells. Blood 110: 2659-2666.

17. Stirewalt DL, Meshinchi S, Radich JP (2003) Molecular targets in acute myelogenous leukemia. Blood Rev 17: 15-23.

18. Spoo AC, Lübbert M, Wierda WG, Burger JA (2007) CXCR4 is a prognostic marker in acute myelogenous leukemia. Blood 109: 786-791.

19. Majeti R, Chao MP, Alizadeh AA, Pang WW, Jaiswal S, et al. (2009) CD47 is an adverse prognostic factor and therapeutic antibody target on human acute myeloid leukemia stem cells. Cell 138: 286-299.

20. Jin L, Hope KJ, Zhai Q, Smadja-Joffe F, Dick JE (2006) Targeting of CD44 eradicates human acute myeloid leukemic stem cells. Nat Med 12: 1167-1174.

21. Hosen N, Park CY, Tatsumi N, Oji Y, Sugiyama H, et al. (2007) CD96 is a leukemic stem cell-specific marker in human acute myeloid leukemia. Proc Natl Acad Sci USA 104: 11008-11013.

22. Hamann PR, Hinman LM, Hollander I, Beyer CF, Lindh D, et al. (2002) Gemtuzumab ozogamicin, a potent and selective anti-CD33 antibodycalicheamicin conjugate for treatment of acute myeloid leukemia. Bioconjug Chem 13: 47-58.

23. Bonnet D (2005) Cancer stem cells: lessons from leukaemia. Cell Prolif 38 357-361.

24. Sutherland HJ, Blair A, Zapf RW (1996) Characterization of a hierarchy in human acute myeloid leukemia progenitor cells. Blood 87: 4754-4761.

25. Blair A, Sutherland HJ (2000) Primitive acute myeloid leukemia cells with longterm proliferative ability in vitro and in vivo lack surface expression of c-kit (CD117). Exp Hematol 28: 660-671. 
Citation: Al-Mawali A (2013) Leukemic Stem Cells Shows the Way for Novel Target of Acute Myeloid Leukemia Therapy. J Stem Cell Res Ther 3: 151. doi:10.4172/2157-7633.1000151

26. Stone RM (2001) Postremission therapy in adults with acute myeloid leukemia. Semin Hematol 38: 17-23.

27. Bonnet D, Bhatia M, Wang JC, Kapp U, Dick JE (1999) Cytokine treatment or accessory cells are required to initiate engraftment of purified primitive human hematopoietic cells transplanted at limiting doses into NOD/SCID mice. Bone Marrow Transplant 23: 203-209.

28. Bhatia M, Bonnet D, Wu D, Murdoch B, Wrana J, et al. (1999) Bone morphogenetic proteins regulate the developmental program of human hematopoietic stem cells. J Exp Med 189: 1139-1148.

29. Bhatia M, Wang JC, Kapp U, Bonnet D, Dick JE (1997) Purification of primitive human hematopoietic cells capable of repopulating immune-deficient mice. Proc Natl Acad Sci USA 94: 5320-5325.

30. Saito Y, Uchida N, Tanaka S, Suzuki N, Tomizawa-Murasawa M, et al. (2010) Induction of cell cycle entry eliminates human leukemia stem cells in a mouse model of AML. Nat Biotechnol 28: 275-280.

31. Al-Mawali A, Gillis D, Hissaria P, Lewis I (2008) Incidence, sensitivity, and specificity of leukemia-associated phenotypes in acute myeloid leukemia using specific five-color multiparameter flow cytometry. Am J Clin Pathol 129: 934945.

32. Al-Mawali A, Gillis D, Lewis I (2009) The role of multiparameter flow cytometry for detection of minimal residual disease in acute myeloid leukemia. Am J Clin Pathol 131: 16-26.

33. Al-Mawali A, Gillis D, Lewis I (2009) The use of receiver operating characteristic analysis for detection of minimal residual disease using five-color multiparameter flow cytometry in acute myeloid leukemia identifies patients with high risk of relapse. Cytometry B Clin Cytom 76: 91-101.

34. Al-Mawali A, To LB, Gillis D, Hissaria P, Mundy J, et al. (2009) The presence of leukaemia-associated phenotypes is an independent predictor of induction failure in acute myeloid leukaemia. Int J Lab Hematol 31: 61-68.

35. Jordan CT, Upchurch D, Szilvassy SJ, Guzman ML, Howard DS, et al. (2000) The interleukin-3 receptor alpha chain is a unique marker for human acute myelogenous leukemia stem cells. Leukemia 14: 1777-1784.

36. Taussig DC, Vargaftig J, Miraki-Moud F, Griessinger E, Sharrock K, et al. (2010) Leukemia-initiating cells from some acute myeloid leukemia patients with mutated nucleophosmin reside in the CD34- fraction. Blood 115: 19761984.

37. Suzuki T, Kiyoi H, Ozeki K, Tomita A, Yamaji S, et al. (2005) Clinical characteristics and prognostic implications of NPM1 mutations in acute myeloid leukemia. Blood 106: 2854-2861.

38. Grisendi S, Pandolfi PP (2005) NPM mutations in acute myelogenous leukemia. N Engl J Med 352: 291-292.

39. Wang JC, Dick JE (2005) Cancer stem cells: lessons from leukemia. Trends Cell Biol 15: 494-501.

40. Guenechea G, Gan OI, Dorrell C, Dick JE (2001) Distinct classes of human stem cells that differ in proliferative and self-renewal potential. Nat Immunol 2: $75-82$

41. Bonnet D (2005) Leukemic stem cells show the way. Folia Histochem Cytobiol 43: $183-186$.

42. Moretti S, Lanza F, Dabusti M, Tieghi A, Campioni D, et al. (2001) CD123 (interleukin 3 receptor alpha chain). J Biol Regul Homeost Agents 15: 98-100.

43. Al-Mawali A, Gillis D, Lewis I (2013) Characteristics and Prognosis of Adult Acute Myeloid Leukaemia with Internal Tandem Duplication in the FLT3 Gene. Oman Med J.

44. Hauswirth AW, Florian S, Printz D, Sotlar K, Krauth MT, et al. (2007) Expression of the target receptor CD33 in CD34+/CD38-/CD123+ AML stem cells. Eur J Clin Invest 37: 73-82.

45. Krauth MT, Bohm A, Agis H, Sonneck K, Samorapoompichit P, et al. (2007) Effects of the CD33-targeted drug gemtuzumab ozogamicin (Mylotarg) on growth and mediator secretion in human mast cells and blood basophils. Exp Hematol 35: 108-116.

46. van Der Velden VH, te Marvelde JG, Hoogeveen PG, Bernstein ID, Houtsmuller $A B$, et al. (2001) Targeting of the CD33-calicheamicin immunoconjugate Mylotarg (CMA-676) in acute myeloid leukemia: in vivo and in vitro saturation and internalization by leukemic and normal myeloid cells. Blood 97: 3197-3204.
47. Valent P, Cerny-Reiterer S, Herrmann H, Mirkina I, George TI, et al. (2010) Phenotypic heterogeneity, novel diagnostic markers, and target expression profiles in normal and neoplastic human mast cells. Best Pract Res Clin Haematol 23: 369-378.

48. Treish IM (2000) Targeting leukemia cells with gemtuzumab ozogamicin Cancer Pract 8: 254-257.

49. Hamann PR, Hinman LM, Beyer CF, Lindh D, Upeslacis J, et al. (2002) An anti-CD33 antibody-calicheamicin conjugate for treatment of acute myeloid leukemia. Choice of linker. Bioconjug Chem 13: 40-46.

50. Matthews DC, Appelbaum FR, Eary JF, Fisher DR, Durack LD, et al. (1999) Phase I study of (131)l-anti-CD45 antibody plus cyclophosphamide and total body irradiation for advanced acute leukemia and myelodysplastic syndrome. Blood 94: 1237-1247.

51. Matthews DC, Martin PJ, Nourigat C, Appelbaum FR, Fisher DR, et al. (1999) Marrow ablative and immunosuppressive effects of 1311-anti-CD45 antibody in congenic and H2-mismatched murine transplant models. Blood 93: 737-745.

52. Sievers EL (2001) Efficacy and safety of gemtuzumab ozogamicin in patients with CD33-positive acute myeloid leukaemia in first relapse. Expert Opin Bio Ther 1: 893-901.

53. Kletting P, Kull T, Bunjes D, Mahren B, Luster M, et al. (2010) Radioimmunotherapy with anti-CD66 antibody: improving the biodistribution using a physiologically based pharmacokinetic model. J Nucl Med 51: 484-491.

54. Fernandez HF, Rowe JM (2010) Induction therapy in acute myeloid leukemia intensifying and targeting the approach. Curr Opin Hematol 17: 79-84.

55. Linenberger ML, Hong T, Flowers D, Sievers EL, Gooley TA, et al. (2001) Multidrug-resistance phenotype and clinical responses to gemtuzumab ozogamicin. Blood 98: 988-994.

56. Vergez F, Green AS, Tamburini J, Sarry JE, Gaillard B, et al. (2011) High levels of CD34+CD38low/-CD123+ blasts are predictive of an adverse outcome in acute myeloid leukemia: a Groupe Ouest-Est des Leucemies Aigues et Maladies du Sang (GOELAMS) study. Haematologica 96: 1792-1798.

57. Nodehi SM, Repp R, Kellner C, Bräutigam J, Staudinger M, et al. (2012) Enhanced ADCC Activity of Affinity Maturated and Fc-Engineered MiniAntibodies Directed against the AML Stem Cell Antigen CD96. PloS One 7 e42426.

58. Goff D, Jamieson C (2010) Cycling toward elimination of leukemic stem cells Cell Stem Cell 6: 296-297.

59. Möhle R, Bautz F, Rafii S, Moore MA, Brugger W, et al. (1998) The Chemokine Receptor CXCR-4 Is Expressed on CD34+Hematopoietic Progenitors and Leukemic Cells and Mediates Transendothelial Migration Induced by Stroma Cell-Derived Factor-1. Blood 91: 4523-4530.

60. Möhle R, Schittenhelm M, Failenschmid C, Bautz F, Kratz-Albers K, et al. (2000) Functional response of leukaemic blasts to stromal cell-derived factor-1 correlates with preferential expression of the chemokine receptor CXCR4 in acute myelomonocytic and lymphoblastic leukaemia. Br J Haematol 110: 563572.

61. Voermans C, van Heese WP, de Jong I, Gerritsen WR, van Der Schoot CE (2002) Migratory behavior of leukemic cells from acute myeloid leukemia patients. Leukemia 16: 650-657.

62. Zeng Z, Shi YX, Samudio IJ, Wang RY, Ling X, et al. (2009) Targeting the leukemia microenvironment by CXCR4 inhibition overcomes resistance to kinase inhibitors and chemotherapy in AML. Blood 113: 6215-6224.

63. Ahn JY, Seo K, Weinberg OK, Arber DA (2013) The Prognostic Value of CXCR4 in Acute Myeloid Leukemia. Appl Immunohistochem Mol Morphol 21: 79-84.

64. Guzman ML, Swiderski CF, Howard DS, Grimes BA, Rossi RM, et al. (2002) Preferential induction of apoptosis for primary human leukemic stem cells. Proc Natl Acad Sci USA 99: 16220-16225.

65. Dash A, Gilliland DG (2001) Molecular genetics of acute myeloid leukaemia Best Pract Res Clin Haematol 14: 49-64.

66. Gilliland DG, Jordan CT, Felix CA (2004) The molecular basis of leukemia ASH Education Book 2004: 80-97.

67. Guzman ML, Jordan CT (2004) Considerations for targeting malignant stem cells in leukemia. Cancer Control 11: 97-104.

68. Guzman ML, Neering SJ, Upchurch D, Grimes B, Howard DS, et al. (2001) 
Citation: Al-Mawali A (2013) Leukemic Stem Cells Shows the Way for Novel Target of Acute Myeloid Leukemia Therapy. J Stem Cell Res Ther 3: 151. doi:10.4172/2157-7633.1000151

Nuclear factor-kappaB is constitutively activated in primitive human acute myelogenous leukemia cells. Blood 98: 2301-2307.

69. Bruserud $\varnothing$, Reikvam H (2010) Therapeutic targeting of NF-kB in myelodysplastic syndromes and acute myeloid leukaemia-the biological heterogeneity. Expert Opin Ther Targets 14: 1139-1142.

70. Jordan CT (2007) The leukemic stem cell. Best Pract Res Clin Haematol 20: 13-18

71. Ebihara Y, Wada M, Ueda T, Xu MJ, Manabe A, et al. (2002) Reconstitution of human haematopoiesis in non-obese diabetic/severe combined immunodeficient mice by clonal cells expanded from single CD34+CD38- cells expressing Flk2/FIt3. Br J Haematol 119: 525-534.

72. Druker BJ, O'Brien SG, Cortes J, Radich J (2002) Chronic myelogenous leukemia. Hematology Am Soc Hematol Educ Program 111-135.

73. Ruggeri BA, Miknyoczki SJ, Singh J, Hudkins RL (1999) Role of neurotrophintrk interactions in oncology: the anti-tumor efficacy of potent and selective trk tyrosine kinase inhibitors in pre-clinical tumor models. Curr Med Chem 6: 845857.

74. Zheng R, Friedman AD, Small D (2002) Targeted inhibition of FLT3 overcomes the block to myeloid differentiation in 32Dcl3 cells caused by expression of FLT3/ITD mutations. Blood 100: 4154-4161.

75. Levis M, Allebach J, Tse KF, Zheng R, Baldwin BR, et al. (2002) A FLT3targeted tyrosine kinase inhibitor is cytotoxic to leukemia cells in vitro and in vivo. Blood 99: 3885-3891.

76. Spiekermann K, Dirschinger RJ, Schwab R, Bagrintseva K, Faber F, et al. (2003) The protein tyrosine kinase inhibitor SU5614 inhibits FLT3 and induces growth arrest and apoptosis in AML-derived cell lines expressing a constitutively activated FLT3. Blood 101: 1494-1504.

77. O'Farrell AM, Abrams TJ, Yuen HA, Ngai TJ, Louie SG, et al. (2003) SU11248 is a novel FLT3 tyrosine kinase inhibitor with potent activity in vitro and in vivo. Blood 101: 3597-3605

78. Weisberg E, Boulton C, Kelly LM, Manley P, Fabbro D, et al. (2002) Inhibition of mutant FLT3 receptors in leukemia cells by the small molecule tyrosine kinase inhibitor PKC412. Cancer Cell 1: 433-443.

79. Smith BD, Levis M, Beran M, Giles F, Kantarjian H, et al. (2004) Single-agent CEP-701, a novel FLT3 inhibitor, shows biologic and clinical activity in patients with relapsed or refractory acute myeloid leukemia. Blood 103: 3669-3676.

80. O'Farrell AM, Foran JM, Fiedler W, Serve H, Paquette RL, et al. (2003) An innovative phase I clinical study demonstrates inhibition of FLT3 phosphorylation by SU11248 in acute myeloid leukemia patients. Clin Cancer Res 9: 5465-5476.

81. Reilly JT (2002) Class III receptor tyrosine kinases: role in leukaemogenesis. $\mathrm{Br} J$ Haematol 116: 744-757.

82. Karp JE, Lancet JE, Kaufmann SH, End DW, Wright JJ, et al. (2001) Clinical and biologic activity of the farnesyltransferase inhibitor R115777 in adults with refractory and relapsed acute leukemias: a phase 1 clinical-laboratory correlative trial. Blood 97: 3361-3369.

83. Gilliland DG, Griffin JD (2002) Role of FLT3 in leukemia. Curr Opin Hemato 9: 274-281.

84. Weisberg E, Barrett R, Liu Q, Stone R, Gray N, et al. (2009) FLT3 inhibition and mechanisms of drug resistance in mutant FLT3-positive AML. Drug Resist Updat 12: 81-89.

85. Galimberti S, Guerrini F, Carulli G, Fazzi R, Palumbo GA, et al. (2004) Significant co-expression of WT1 and MDR1 genes in acute myeloid leukemia patients at diagnosis. Eur J Haematol 72: 45-51.

86. Gilliland DG, Griffin JD (2002) The roles of FLT3 in hematopoiesis and leukemia. Blood 100: 1532-1542.

87. Kelly LM, Liu Q, Kutok JL, Williams IR, Boulton CL, et al. (2002) FLT3 internal tandem duplication mutations associated with human acute myeloid leukemias induce myeloproliferative disease in a murine bone marrow transplant model. Blood 99: 310-318.
88. Orlowski RZ, Stinchcombe TE, Mitchell BS, Shea TC, Baldwin AS, et al. (2002) Phase I trial of the proteasome inhibitor PS-341 in patients with refractory hematologic malignancies. J Clin Oncol 20: 4420-4427.

89. Mesters RM, Padro T, Bieker R, Steins M, Kreuter M, et al. (2001) Stable remission after administration of the receptor tyrosine kinase inhibitor SU5416 in a patient with refractory acute myeloid leukemia. Blood 98: 241-243.

90. Sukhai MA, Prabha S, Hurren R, Rutledge AC, Lee AY, et al. (2013) Lysosomal disruption preferentially targets acute myeloid leukemia cells and progenitors. J Clin Invest 123: 315-328

91. Ochi T, Fujiwara H, Suemori K, Azuma T, Yakushijin Y, et al. (2009) Aurora-A kinase: a novel target of cellular immunotherapy for leukemia. Blood 113: 66 74.

92. Ikezoe T, Yang J, Nishioka C, Tasaka T, Taniguchi A, et al. (2007) A nove treatment strategy targeting Aurora kinases in acute myelogenous leukemia. Mol Cancer Ther 6: 1851-1857.

93. Kim SJ, Jang JE, Cheong JW, Eom JI, Jeung HK, et al. (2012) Aurora A kinase expression is increased in leukemia stem cells, and a selective Aurora A kinase inhibitor enhances Ara-C-induced apoptosis in acute myeloid leukemia stem cells. Korean J Hematol 47: 178-185.

94. Yang J, Ikezoe T, Nishioka C, Nobumoto A, Udaka K, et al. (2013) CD34+ CD38- acute myelogenous leukemia cells aberrantly express Aurora kinase A. Int J Cancer.

95. Kasper S, Breitenbuecher F, Heidel F, Hoffarth S, Markova B, et al. (2012) Targeting MCL-1 sensitizes FLT3-ITD-positive leukemias to cytotoxic therapies. Blood Cancer J 2: e60

96. Yoshimoto G, Miyamoto T, Jabbarzadeh-Tabrizi S, lino T, Rocnik JL, et al. (2009) FLT3-ITD up-regulates MCL-1 to promote survival of stem cells in acute myeloid leukemia via FLT3-ITD-specific STAT5 activation. Blood 114: 5034 5043.

97. Glaser SP, Lee EF, Trounson E, Bouillet P, Wei A, et al. (2012) Anti-apoptotic $\mathrm{Mcl}-1$ is essential for the development and sustained growth of acute myeloid leukemia. Genes Dev 26: 120-125.

98. Bose P, Grant S (2013) Mcl-1 as a therapeutic target in acute myelogenous leukemia (AML). Leuk Res Rep 2: 12-14.

99. Kikushige $\mathrm{Y}$, Akashi K (2012) TIM-3 as a therapeutic target for malignant stem cells in acute myelogenous leukemia. Ann N Y Acad Sci 1266: 118-123.

100. Kikushige Y, Shima T, Takayanagi S-i, Urata S, Miyamoto T, et al. (2010) TIM3 Is a Promising Target to Selectively Kill Acute Myeloid Leukemia Stem Cells. Cell Stem Cell 7: 708-717.

101. Florian S, Sonneck K, Hauswirth AW, Krauth MT, Schernthaner GH, et al. (2006) Detection of molecular targets on the surface of CD34+/CD38-stem cells in various myeloid malignancies. Leuk Lymphoma 47: 207-222.

102. de Jonge $H$, Woolthuis $C$, Vos A, Mulder A, van den Berg E, et al. (2011) Gene expression profiling in the leukemic stem cell-enriched CD34+ fraction identifies target genes that predict prognosis in normal karyotype AML. Leukemia 25: 1825-1833.

103. Grant S (2008) Is the focus moving toward a combination of targeted drugs? Best Pract Res Clin Haematol 21: 629-637.

104. Foran JM, Norton AJ, Micallef IN, Taussig DC, Amess JA, et al. (2001) Loss of CD20 expression following treatment with rituximab (chimaeric monoclona anti-CD20): a retrospective cohort analysis. Br J Haematol 114: 881-883. 